\title{
INTERNAL LOCUS OF CONTROL DAN SELF-EFFICACY PEMAIN BOLA BASKET DALAM MELAKUKAN FREE THROW
}

\author{
Agus Iwan Setiawan, Yunita Kurniawati, Afia Fitriani \\ agusiwaan@gmail.com \\ Program Studi Psikologi, Fakultas Ilmu Sosial dan Ilmu Politik \\ Universitas Brawijaya
}

\begin{abstract}
ABSTRAK
Penelitian ini bertujuan untuk melihat peran internal locus of control terhadap selfefficacy pemain bola basket dalam melakukan free throw. Metode penelitian yang digunakan adalah metode kuantitatif. Responden dalam penelitian ini adalah pemain bola basket yang terdaftar dalam turnamen National Basketball League (NBL) Seri X di Surabaya. Teknik pengambilan data yang digunakan adalah simple random sampling dengan subjek berjumlah 78 pemain. Data diperoleh melalui dua alat ukur, yaitu skala internal locus of control berdasarkan teori Rotter (Wirtama, 2014) dan skala self-efficacy berdasarkan teori Albert Bandura yang disusun oleh Wirtama (2014) dan dimodifikasi oleh peneliti. Pengolahan data penelitian menggunakan analisis regresi sederhana. Hasil penelitian menunjukkan bahwa internal locus of control berperan secara signifikan terhadap self-efficacy pemain bola basket dalam melakukan free throw dengan memberikan kontribusi sebanyak 39.1\%.
\end{abstract}

Kata Kunci: Free Throw, Internal Locus of Control, Pemain Bola Basket, Self-Efficacy

Permainan bola basket merupakan salah satu cabang olahraga yang paling banyak digemari, karena hampir seluruh dunia mengenal dan memainkan olahraga bola basket. Berkaitan dengan ini Haris (Taryono, 2010) menjelaskan bahwa bola basket adalah permainan beregu yang masing-masing regu terdiri dari lima orang pemain di lapangan, permainan bola basket dimainkan dengan menggunakan lengan. Cara main dari permainan bola basket adalah pemain memasukkan bola sebanyak-banyaknya ke jaring pada ring lawannya dan berusaha menjaga jaring pada ring sendiri, agar tidak kemasukan. Suatu regu dinyatakan menang apabila regu tersebut dapat memasukkan bola terbanyak ke jaring pada ring lawannya.

Setiap pemain bola basket sebelum terlibat dalam suatu pertandingan harus mempunyai kondisi fisik, kemampuan teknik, startegi dalam bermain dan mental yang prima (Candi, 2013). Agar pemain dapat berprestasi secara maksimal, seorang pemain harus mempunyai kondisi fisik dan psikis yang memadai. Di dalam permainan bola basket terdapat beberapa teknik dasar yang harus dikuasai oleh setiap pemain, seperti mengoper dan menangkap bola (pasing and cathing ball), menggiring bola dengan tangan (dribbling), serta kemampuan menembak bola menuju ring (shooting). Penguasaan teknik tersebut merupakan syarat utama dalam bermain basket, karena tanpa menguasai teknik tersebut seorang pemain tidak akan dapat bermain basket dengan baik dan benar dan pemain tidak akan mencapai prestasi yang tinggi. 
Menurut Pesurnay (2000) menyebutkan prestasi ditentukan oleh keadaan psikis olahragawan artinya bahwa prestasi olahraga ditentukan oleh aspek psikis, karena faktor psikislah yang menentukan pemenang suatu pertandingan. Faktor psikis yang dimaksudkan adalah kemampuan atlet untuk tampil dengan baik dalam keadaan yang diwarnai ketegangan serta persaingan seperti dalam pertandingan olahraga prestasi (Gunarsa, 1996). Selain faktor psikis, faktor fisik juga diperlukan dalam menunjang perstasi. Harsono (1988) menjelaskan bahwa kondisi fisik atlet memegang peranan yang sangat penting dalam program latihannya. Program latihan kondisi fisik haruslah direncanakan secara baik dan sistematis dan ditujukan untuk meningkatkan kesegaran jasmani dan kemampuan fungsional dari sistem tubuh sehingga dengan demikian memungkinkan atlet untuk mencapai prestasi yang lebih baik.

Demi mencapai prestasi dicabang olahraga bola basket maka penguasaan bentuk latihan, teknik maupun taktik dalam permainan bola basket perlu dikuasai oleh setiap pemain, sebab teknik dan taktik adalah dua bagian khusus yang harus diolah para pemain bola basket. Salah satu teknik yang harus dikuasai oleh setiap pemain bola basket adalah free throw. Free throw diperoleh saat salah satu pemain lawan melakukan pelanggaran kepada pemain yang akan memasukkan bola ke dalam jaring. Berdasarkan data statistik free throw yang diperoleh dari National Basketball League (NBL) Indonesia season 2013-2014, terdapat 7.535 kesempatan free throw dari 396 pertandingan yang dijalani oleh 12 klub. Setiap klub menjalani 33 kali pertandingan, sehingga diperoleh rata-rata peluang terjadinya free throw pada satu pertandingan sebanyak 19.03 free throw (Anonim, 2014). Data tersebut menunjukkan betapa pentingnya penguasaan free throw pada setiap pemain. Menurut Sodikun (Wicaksono \& Lakmiwati, 2013) free throw merupakan hadiah yang diberikan kepada sesorang pemain untuk mencetak angka. Memasukan satu free throw tidak hanya menambah satu poin, melainkan juga dapat menjatuhkan mental lawan karena untuk mendapatkan poin selain dari free throw sangat sulit karena akan ada hadangan dari pemain lawan.

Melakukan free throw juga bukan perkara mudah, terlihat masih ada pemain yang gagal memasukan free throw, padahal free throw merupakan teknik dasar pada permainan bola basket. Banyak pemain dan pelatih yang merasakan adanya tekanan dari penonton saat melakukan free throw, sehingga merasa kapasitas mental pemain yang sedang diserang oleh penonton. Contoh dari kegagalan free throw diungkapkan pelatih Tim Nasional Basketball Indonesia (Anonim, 2012) setelah mengalami kekalahan dalam pertandingan Asean Basketball League (ABL) melawan Air Asia Philippine Patriot pada 10 Maret 2012. Pelatih TIMNAS kala itu John Todd Purves menilai kekalahan ini tidak lepas dari kegagalan anak asuhnya dalam melakukan tembakan bebas (free throw) pada saat-saat penting. Todd juga menjelaskan bawa kemampuan free throw pemainnya sangat buruk, pemain juga mempunyai masalah mengenai kekuatan mental mereka sehingga free throw yang 
mereka lakukan tidak berjalan dengan baik (Anonim, 2012).

Pertandingan final NBL 2015, SM Britama dapat memenangkan pertandingan dan meraih gelar juara setelah melawan Pelita Jaya pada bulan Mei 2015. Pahlawan SM Britama saat itu adalah Rony Gunawan menjadi penentu berkat konsentrasinya yang membuahkan poinpoin tambahan untuk SM Britama melalui peluang free throw (Wardhana, 2015). Konsentrasi penuh dan keyakinan serta pengalaman seperti Roni Gunawan itulah yang dibutuhkan oleh setiap pemain bola basket agar dapat mencapai prestasi yang tinggi. Oleh karena itu, pemain bola basket membutuhkan kepribadian yang dapat mengontrol dirinya dari tekanan tinggi dari penonton, stres, provokasi dari pemain lawan, dan lain sebagainya. Tipe kepribadian yang mampu menghadapi situasi dengan tekanan tinggi yaitu internal locus of control.

Kepribadian internal locus of control pada setiap pemain sangatlah penting, karena internal locus of control berasal dari dalam diri pemain mengenai keyakinan akan kemampuan, keterampilan dan usaha yang telah mereka lakukan, sehingga dengan keyakinan dalam diri yang tinggi, faktor dari luar diri pemain tidak akan banyak mempengaruhi keyakinan pemain untuk melakukan tugas dengan baik dikarenakan pemain tersebut dapat mengontrol dirinya dalam menghadapi tekanan dari luar mapun dari dalam diri pemain tersebut. Kepribadian internal locus of control yang dimiliki pemain diharapkan mampu mengatasi kondisi stress, memiliki kontrol perasaan yang baik, dan mampu menghadapi tantangan dalam hidup yaitu berupa tuntutan untuk melakukan free throw dengan baik.

Menurut Larsen dan Buss (Zulkaida, Kurniati, Muluk, \& Rifameutia, 2007) menyatakan bahwa locus of control merupakan suatu konsep yang menunjuk pada keyakinan individu mengenai peristiwa-peristiwa yang terjadi dalam hidupnya. Locus of control menggambarkan seberapa jauh seseorang memandang hubungan antara perbuatan (action) sebagai sebab yang dilakukannya dan dengan hasil (outcome) sebagai akibatnya. Selanjutnya Rotter (Zulkaida, dkk. 2007) membedakan orientasi locus of control menjadi dua, yaitu internal locus of control dan eksternal locus of control. Individu dengan internal LOC cenderung menganggap bahwa keterampilan (skill), kemampuan (ability), dan usaha (effort) lebih menentukan apa yang mereka peroleh dalam hidup mereka. ketika salah satu pemain mendapatkan free throw, banyak tekanan yang akan didapatkan oleh pemain tersebut. Tekanan yang timbul tersebut berasal dari teriakan penonton, provokasi dari pemain lawan, ketakutan akan kegagalan menjalankan free throw, dan lain-lain. Tekanan tersebut dapat diatasi apabila pemain mempunyai internal locus of control yang tinggi, usaha, melatih keterampilan dan melatih kemampuan teknik basket mereka serta melatih mental mereka agar siap menghadapi tekanan saat menjalani suatu pertandingan khususnya saat menghadapi situasi free throw.

Selain itu, saat proses untuk melakukan free throw dengan baik dan tepat saat menghadapi tekanan dari penonton diperlukan keyakinan dan kepercayaan diri dari pemain itu sendiri. Keyakinan terhadap kemampuannya dalam 
menyelesaikan tugas biasanya disebut dengan self-efficacy. Bandura (Zulkaida dkk, 2007) mengungkapkan bahwa, selfefficacy adalah keyakinan seseorang tentang kemampuannya untuk mengatur dan melakukan tindakan-tindakan yang perlu dalam mencapai tingkat kinerja tertentu. Dengan self-efficacy yang tinggi akan membuat seseorang akan berusaha semakin giat.

Bandura (Wicaksono \& Lakmiwati, 2013) menyebutkan bahwa di berbagai penelitian menunjukkan kualitas individu akan meningkat seiring pertumbuhan selfefficacy. Jadi, meskipun pemain mendapatkan tekanan saat melakukan free throw, pemain yang memiliki self-efficacy tinggi akan mampu menyelesaikan free throw dengan baik, begitu juga sebaliknya. Akan tetapi self-efficacy yang tinggi (keyakinan yang tinggi) saja tidak cukup untuk menyelesaikan tugas dengan baik, dibutuhkan pula internal locus of control yang tinggi pula pada setiap pemain, karena dengan internal locus of control pemain dapat melatih kemampuan, keterampilan dan usanyanya menjadi lebih baik, sehingga internal locus of control yang tinggi dapat berperan bersama-sama dengan self-efficacy yang tinggi untuk menyelesaikan tugas yakni free throw dengan baik.

Berdasarkan dari uraian latar belakang tersebut, penulis ingin mengetahui apakah internal locus of control memiliki pengaruh pada selfefficacy pemain basket pada saat melakukan free throw, sehingga peneliti mencoba melakukan penelitian dengan judul "Peran Internal Locus of Control terhadap Self-Efficacy Pemain Bola Basket dalam Melakukan Free throw".
Hipotesis dalam penelitian ini adalah "Internal locus of control berperan terhadap self-efficacy pemain bola basket dalam melakukan free throw".

\section{METODE}

\section{Desain Penelitian}

Desain penelitian yang digunakan dalam penelitian ini adalah dengan menggunakan pendekatan kuantitatif dengan metode analisis regresi linier sederhana. Penelitian dengan pendekatan kuantitatif menekankan analisisnya pada data-data numerical (angka) yang diolah dengan metode statistika (Azwar, 2013). Penelitian ini dilakukan dengan tujuan untuk melihat peran internal locus of control terhadap self-efficacy pemain bola basket dalam melakukan free throw.

\section{Subjek Penelitian}

Jumlah sampel dalam penelitian berjumlah 78 pemain bola basket yang terdiri dari delapan klub bola basket, yaitu sembilan dari klub Aspac, 11 dari klub Bima Sakti, tujuh dari klub CLS Knight, 13 dari klub Garuda Bandung, 12 dari klub HANGTUAH, 11 dari klub NSH, 10 dari klub Pelita Jaya, dan lima dari klub STADIUM Bandung.

\section{Instrument Penelitian}

\section{Skala Internal Locus of Control}

Skala internal locus of control merupakan modifikasi dari Wirtama (2014) yang disusun berdasarkan teori dari Julian Rotters (Budiwati, 2012). Setelah dilakukan tryout didapatkan 10 aitem yang lolos dari 13 aitem yang ujikan dengan nilai cronbach alpha 0,812 . 
2. Skala Self-efficacy

Skala self-efficacy merupakan modifikasi dari Wirtama (2014) yang disusun berdasarkan teori dari Albert Bandura (Ghufron \& Risnawita, 2012). Setelah dilakukan tryout seluruh aitem dinyatakan lolos yang berjumlah 18 aitem dengan nilai cronbach alpha 0,887 .

\section{Analisis Data}

Tahap analisa data dilakukan dengan melalui uji normalitas One-Sampel Kolmogorov-Smirnov, uji linieritas dengan mencari persamaan garis regresi variabel $\mathrm{X}$ terhadap variabel $\mathrm{Y}$, kriteria pengujian linieritas adalah apabila nilai signifikasi lebih kecil dari 0,05, uji heteroskedastisitas bertujuan untuk menguji apakah dalam model regresi terjadi ketidaksamaan varian dari residual satu pengamatan ke pengamatan yang lain. Uji hipotesis menggunakan analisis regresi linier sederhana dengan bantun program Statistical Package For the Social Science (SPSS) for Windows 22.0.

\section{HASIL}

\section{Analisis Deskriptif}

Analisis deskriptif dilakukan dengan cara mengkategorikan subjek penelitian. Tabel analisis deskriptif berdasarkan kategori data demografis subjek penelitian dapat dilihat pada tabel di bawah ini:
Tabel 1.

Deskripsi Data Variabel Penelitian

\begin{tabular}{|c|c|c|c|}
\hline Skala & Statistik & Hipotetik & Empirik \\
\hline \multirow{7}{*}{$\begin{array}{l}\text { Internal } \\
\text { Locus of } \\
\text { Control }\end{array}$} & Nilai & 10 & 24 \\
\hline & Minimal & & \\
\hline & Nilai & 40 & 40 \\
\hline & Maksimal & & \\
\hline & Standar & 5 & 3,89 \\
\hline & Deviasi & & \\
\hline & Mean $(\mu)$ & 25 & 33,6 \\
\hline \multirow{6}{*}{$\begin{array}{l}\text { Self- } \\
\text { Efficacy }\end{array}$} & Nilai & 18 & 43 \\
\hline & Minimal & & \\
\hline & Nilai & 72 & 71 \\
\hline & Maksimal & & \\
\hline & $\begin{array}{l}\text { Standar } \\
\text { Deviasi }\end{array}$ & 9 & 6,79 \\
\hline & Mean $(\mu)$ & 45 & 56,67 \\
\hline
\end{tabular}

Berdasarkan skor empirik dan hipotetik tersebut, dapat diperoleh gambaran mengenai variabel $\mathrm{X}$ (internal locus of control) dan variabel Y (selfefficacy dalam melakukan free throw). Untuk mengetahui kategorinya, disusun sebuah norma berdasarkan ketentuan kategorisasi jenjang berdasarkan subjek penelitian (Azwar, 2012).

Berdasarkan perhitungan tersebut, maka pada variabel X (internal locus of control) dan variabel Y (self-efficacy dalam melakukan free throw) dengan jumlah subjek 78 pemain diperoleh kategorisasi seperti di bawah ini.

Tabel 2.

Norma Variabel X dan Y

\begin{tabular}{lllcc}
\hline \multicolumn{1}{c}{ Skala } & $\begin{array}{c}\text { Daerah } \\
\text { Keputusan }\end{array}$ & Kategori & $\begin{array}{c}\text { Jumlah } \\
\text { Subjek }\end{array}$ & $\%$ \\
\hline $\begin{array}{l}\text { Internal } \\
\text { Locus }\end{array}$ & $\mathrm{X}<20$ & Rendah & 0 & $0 \%$ \\
of & $20<\mathrm{X}<$ & Sedang & 9 & $11,54 \%$ \\
Control & 30 & & & \\
Self- & $30<\mathrm{X}$ & Tinggi & 69 & $88,46 \%$ \\
Efficacy & $36<36$ & Rendah & 0 & $0 \%$ \\
& 54 & Sedang & 29 & $37,18 \%$ \\
& $54<\mathrm{X}$ & Tinggi & 49 & $62,82 \%$ \\
\hline
\end{tabular}


Berdasarkan tabel 2 diketahui bahwa tidak ada subjek yang memiliki internal locus of control rendah, 9 pemain memiliki internal locus of control sedang, dan sisanya sebanyak 69 pemain memiliki internal locus of control tinggi. Untuk variabel self-efficacy pemain bola basket dalam melakukan free throw, tidak ada pemain yang memiliki self-efficacy rendah, 29 pemain memiliki self-efficacy sedang, dan sisanya 49 pemain memiliki selfefficacy tinggi.

Tabel 3.

Kategorisasi posisi

\begin{tabular}{|c|c|c|c|c|c|c|}
\hline \multirow[t]{2}{*}{ Posisi } & \multicolumn{3}{|c|}{$\begin{array}{l}\text { Kategorisasi internal } \\
\text { locus of control }\end{array}$} & \multicolumn{3}{|c|}{$\begin{array}{l}\text { Kategorisasi self- } \\
\text { efficacy pemain bola } \\
\text { basket dalam } \\
\text { melakukan free } \\
\text { throw }\end{array}$} \\
\hline & $\begin{array}{l}\text { Ren- } \\
\text { dah }\end{array}$ & $\begin{array}{l}\text { Se- } \\
\text { dang }\end{array}$ & $\begin{array}{l}\text { Ti- } \\
\text { nggi }\end{array}$ & $\begin{array}{l}\text { Ren- } \\
\text { dah }\end{array}$ & $\begin{array}{l}\text { Se- } \\
\text { dang }\end{array}$ & $\begin{array}{l}\text { Ti- } \\
\text { nggi }\end{array}$ \\
\hline Center & 0 & 1 & 9 & 0 & 5 & 5 \\
\hline $\begin{array}{l}\text { For- } \\
\text { ward }\end{array}$ & 0 & 6 & 25 & 0 & 11 & 17 \\
\hline Guard & 0 & 2 & 34 & 0 & 12 & 24 \\
\hline Total & - & 9 & 69 & - & 28 & 50 \\
\hline
\end{tabular}

Berdasarkan tabel 3 menunjukkan bahwa posisi center hanya 1 pemain dari 10 pemain yang memiliki internal locus of control sedang, sedangkan 9 pemain lainnya memiliki internal locus of control tinggi. Untuk kategorisasi self-efficacy

\section{Uji Normalitas}

Berikut adalah hasil dari uji normalitas yang dilakukan oleh peneliti:

Tabel 4.

Uji normalitas

\begin{tabular}{lll}
\hline $\begin{array}{l}\text { Kolmogorov- } \\
\text { Smirnov (KS) }\end{array}$ & Signifikansi & Bentuk \\
\hline 0,98 & $0,062(\mathrm{p}>0,05)$ & Normal \\
\hline
\end{tabular}

Berdasarkan uji KolmogorovSmirnov didapatkan taraf signifikansi atau nilai $p$-value variabel self-efficacy dalam melakukan free throw sebesar 0,062 dan nilai tersebut lebih besar dari $\alpha=0,05$. Pengujian tersebut menunjukkan bahwa residual memiliki distribusi normal.

\section{Uji Linieritas}

Berikut adalah hasil dari uji linearitas yang dilakukan oleh peneliti:

Tabel 5.

Uji linieritas

\begin{tabular}{lccc}
\multicolumn{1}{c}{ Variabel } & Signifikansi & $\begin{array}{c}\text { Linierity } \\
(\mathbf{F})\end{array}$ & Keterangan \\
\hline $\begin{array}{l}\text { Internal } \\
\text { locus of }\end{array}$ & 0,000 & 42,995 & Linier \\
control & & & \\
self-efficacy & & & \\
\hline Keterangan: $(*)=$ Terhadap & &
\end{tabular}

Berdasarkan tabel di atas, dapat diketahui bahwa uji linieritas antara variabel internal locus of control dan selfefficacy pemain bola basket dalam melakukan free throw memiliki nilai $\mathrm{F}$ sebesar 42,995 dengan nilai signifikansi 0,000 yang nilainya lebih kecil dari 0,05 . Hasil tersebut menunjukkan bahwa variabel internal locus of control memiliki hubungan yang linier dengan variabel selfefficacy pemain bola basket dalam melakukan free throw.

\section{Uji Heteroskedastisitas}

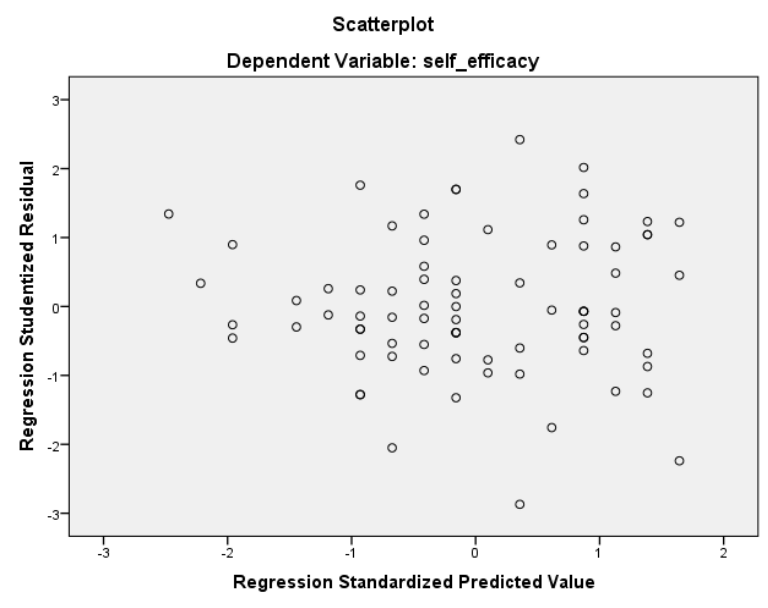




\section{Uji Hipotesis}

Uji hipotesis menggunakan analisis regresi linier sederhana. Hasil dari uji regresi linier sederhana dapat dilihat pada tabel berikut:

Tabel 6.

Uji hipotesis

\begin{tabular}{ccccc}
\hline $\begin{array}{c}\mathbf{R} \\
\text { Square }\end{array}$ & $\begin{array}{c}\mathbf{F} \\
\text { Hitung }\end{array}$ & $\begin{array}{c}\mathbf{F} \\
\text { Tabel }\end{array}$ & $\begin{array}{c}\text { Signifi- } \\
\text { kansi }\end{array}$ & Ket. \\
\hline 0,391 & 48,717 & 3,97 & 0,000 & Signifikan \\
\hline
\end{tabular}

Berdasarkan tabel diatas menunjukkan

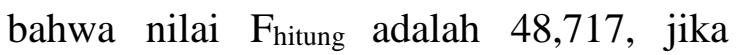
dibandingkan dengan $F_{\text {tabel }}$ yakni 3.97 maka nilai tersebut lebih besar $(48,717>$ 3.97) sehingga dapat disimpulkan bahwa hipotesis diterima atau dengan kata lain terdapat peran antara internal locus of control terhadap self-efficacy.

Berdasarkan hasil olah data aplikasi Statistical Package For the Social Science (SPSS) for Windows 22.0 dapat diketahui nilai signifikansinya adalah 0,000 yang lebih kecil dari $\alpha(0,05)$. Oleh karena itu $\mathrm{H}_{\mathrm{a}}$ diterima. Kesimpulannya bahwa internal locus of control berperan terhadap self-efficacy pemain bola basket dalam melakukan free throw.

Selain uji hipotesis, dapat diketahui sumbangan dari variabel $\mathrm{X}$ terhadap $\mathrm{Y}$ melalui nilai regresi ditunjukkan pada nilai $R$ square yakni 0,391. Hal ini menunjukkan bahwa internal locus of control memiliki peran 39,1\% terhadap self-efficacy pemain bola basket dalam melakukan free throw, sedangkan sisanya $60.9 \%$ dipengaruhi oleh faktor lain.

\section{DISKUSI}

Berdasarkan hasil penelitian menunjukkan bahwa hipotesis peneliti diterima, hal ini dilihat dari nilai $F_{\text {hitung }}$ adalah 48,717, jika dibandingkan dengan $F_{\text {tabel }}$ yakni 3.97 maka nilai tersebut lebih besar $(48,717>3.97)$, serta dilihat dari nilai signifikansi sebesar 0,000 yang berarti signifikan, sehingga dapat disimpulkan bahwa hipotesis diterima atau dengan kata lain terdapat peran antara internal locus of control terhadap selfefficacy pemain bola basket dalam melakukan free throw. Hal ini dikarenakan apabila individu yang mempunyai keterampilan (skill), kemampuan (ability), dan usaha (effort) yang tinggi maka selfefficacy pemain bola basket dalam melakukan free throw akan tinggi juga, karena individu tersebut mempunyai keyakinan yang tinggi akan kemampuan dalam diri sendiri sehingga berpengaruh terhadap keyakinan pada individu tersebut untuk melakukan free throw dengan baik. Self-efficacy yang tinggi akan membuat seseorang berusaha semakin giat, di berbagai penelitian menunjukkan kualitas individu akan mengalami peningkatan seiring pertumbuhan self-efficacy (Bandura, 1997). Pernyataan ini sejalan dengan penelitian yang dilakukan Wicaksono \& Laksmiwati (2013) menyebutkan bahwa semakin tinggi selfefficacy maka semakin tinggi pula ketepatan free throw.

Berdasarkan tabel 6 menyatakan

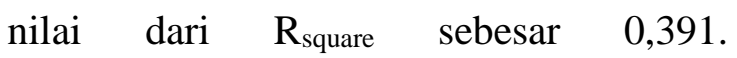
Berdasarkan nilai tersebut dapat dikatakan bahwa $\mathrm{R}_{\text {square }}$ bernilai positif sehingga dapat dikatakan bahwa terdapat pengaruh positif dari internal locus of control terhadap self-efficacy pemain bola basket dalam melakukan free throw. Artinya adalah semakin tinggi tingkat internal locus of control yang dimiliki oleh pemain bola basket, maka akan semakin tinggi pula self-efficacy yang akan muncul. Jika 
dilihat dari kategorisasi subjek pada tabel 2, mayoritas subjek memiliki internal locus of control tinggi, yang berarti subjek dalam penelitian ini menganggap keyakinan subjek mengenai sumber penentu dari peristiwa atau kejadian dalam hidupnya tersebut dipengaruhi oleh usaha dan tingkah lakunya sendiri.

Jika dilihat dari faktor yang mempengaruhi internal locus of control, usia adalah salah satu faktor penting yang mempengaruhi nilai internal locus of control dalam penelitian ini tinggi. Apabila dilihat dari segi usia, para pemain berada pada masa dewasa awal karena usia para pemain berada pada rentang 19 - 38 tahun. Menurut Hurlock (2002) masa dewasa awal berlangsung antara usia 18 40 tahun. Hal ini sesuai dengan pernyataan Schultz \& Schultz (2002) yang menyebutkan bahwa usia merupakan salah satu faktor yang mempengaruhi berkembangnya locus of control, karena locus of control terbentuk sejak masa kanak-kanak dan semakin dewasa, seseorang akan menjadi semakin internal.

Berdasarkan kategorisasi selfefficacy, pada tabel 2 menunjukkan bahwa nilai self-efficacy mayoritas berada pada kategori tinggi, yang berarti keyakinan subjek pada penelitian ini terhadap kemampuannya atau kompetensi dirinya dalam melakukan suatu tugas sehingga dapat mencapai tujuan yang diharapkan tinggi. Tingginya kategorisasi internal locus of control dan self-efficacy pada mayoritas subjek mendukung pernyataan sebelumnya bahwa memang terdapat peran positif antara internal locus of control terhadap self-efficacy pemain bola basket dalam melakukan free throw. Jika dilihat dari beberapa faktor yang mempengaruhi self-efficacy, insentif eksternal merupakan salah faktor yang dapat menunjang nilai self-efficacy para pemain tinggi. Insentif eksternal yang dimaksud adalah insentif yang diberikan orang lain atau manajemen dari tim berupa bonus, tunjangan, dan gaji.

Faktor selanjutnya adalah status atau peran individu dalam lingkungan, lingkungan yang dimaksud adalah tim basket dari para pemain, sedangkan peran yang dimaksud adalah posisi dari pemain. Pada tabel 3, posisi yang menyumbang nilai tertinggi dari self-efficacy adalah Guard dengan 24 dari 36 pemain. Hal ini didukung dengan hasil statistik NBL Regular Season 2014-2015 yang menunjukkan bahwa dari 10 pemain yang memiliki prosentase melakukan free throw terbaik didominasi oleh 6 pemain yang berada pada posisi Guard (Anonim, 2015). Pada posisi ini biasanya diisi oleh pemain yang memiliki postur tubuh yang relatif lebih rendah di dalam tim dan posisi ini dibagi menjadi dua, yakni Point Guard dan Shooting Guard. \

Faktor selanjutnya adalah informasi mengenai kemampuan diri, individu memiliki self-efficacy tinggi jika individu tersebut memperoleh informasi positif mengenai dirinya, dan sebaliknya individu akan memiliki self-efficacy rendah jika memperoleh informasi yang negatif tentang dirinya. Berdasarkan kategorisasi pada tabel 2, nilai self-efficacy berada pada kategori tinggi yang berarti para pemain memperoleh informasi positif mengenai dirinya.

Berdasarkan hasil analisis data tersebut mempunyai kaitan yang erat dengan teori Rotters (Zulkaida dkk, 2007) yang menyatakan bahwa individu dengan internal locus of control cenderung menganggap bahwa keterampilan (skill), kemampuan (ability), dan usaha (effort) 
lebih menentukan apa yang mereka peroleh dalam hidup mereka. Sementara itu, Larsen \& Buss (Zulkaida dkk, 2007) menyatakan bahwa locus of control merupakan suatu konsep yang menunjuk pada keyakinan individu mengenai peristiwa-peristiwa yang terjadi dalam hidupnya. Locus of control menggambarkan seberapa jauh seseorang memandang hubungan antara perbuatan (action) sebagai sebab yang dilakukannya dengan hasil (outcome) sebagai akibatnya

Berdasarkan pada dimensi kemampuan (ability), pemain bola basket percaya pada kemampuan yang mereka miliki. Para pemain beranggapan bahwa kesuksesan maupun kegagalan dalam mencetak angka melalui free throw sangat dipengaruhi oleh kemampuannya sendiri. Dalam dimensi minat, untuk dapat mempengaruhi self-efficacy, pemain yang mempunyai kesempatan melakukan free throw memiliki minat yang lebih besar terhadap control perilaku, peristiwa dan tidakan mereka pada saat melakukan free throw, sehingga pemain akan bekerja keras dan memiliki kemauan yang tinggi untuk mencapai suatu tujuan yang diinginkan.

$$
\text { Pemain yang mempunyai }
$$
kesempatan melakukan free throw yang memiliki usaha (effort) akan bersikap pantang menyerah dan akan berusaha semaksimal mungkin untuk dapat mengontrol perilaku mereka, hal tersebut juga dapat mempengaruhi self-efficacy yang dimilikinya. Begitu juga pemain dengan internal locus of control akan mampu mengoptimalkan keterampilan, kemampuan, dan usaha yang sudah dimilikinya untuk meningkatkan keberhasilan dalam melakukan free throw. Setiap pemain yang yakin akan kemampuan yang dimilikinya atau memiliki internal locus of control yang tinggi akan meningkatkan self-efficacy dalam melakukan free throw, karena individu tersebut sudah merasa memiliki kemampuan yang cukup dari hasil latihan, kemampuan, keterampilan, dan usaha yang sudah mereka lakukan. Hal ini sesuai penelitian Wicaksono \& Laksmiwati (2013) diketahui bahwa pemain yang mempunyai self-efficacy tinggi mampu mengatasi tekanan yang ada, sehingga pemain dapat berhasil melakukan free throw

Menurut Wicaksono \& Laksmiwati (2013) peran self-efficacy dianggap penting, karena dengan self-efficacy tekanan yang dirasakan pemain saat pertandingan dapat teratasi. Hal ini sesuai dengan Fiest \& Fiest (Wicaksono \& Laksmiwati, 2013) yang menyatakan selfefficacy tinggi merasa mampu mengatasi rintangan dan menganggap ancaman sebagai suatu tantangan yang tidak perlu dihindari. Para pemain bola basket yang memilki self-efficacy tinggi tidak akan menyia-nyiakan kesempatan untuk melakukan free throw.

\section{KESIMPULAN}

Internal locus of control berperan terhadap self-efficacy pemain bola basket dalam melakukan free throw dengan $R$ square sebesar 0,391, yang berarti internal locus of control memiliki peran sebesar $39,1 \%$ terhadap self-efficacy pemain bola basket dalam melakukan free throw, sedangkan $60,9 \%$ dipengaruhi oleh faktor lain.

78 pemain yang menjadi subjek dalam penelitian ini, diketahui bahwa subjek memiliki internal locus of control mayoritas berada pada kategori tinggi sebanyak $88.46 \%$, sisanya berada pada 
kategori sedang sebanyak $11.54 \%$. Begitu juga pada self-efficacy mayoritas tergolong dalam kategori tinggi sebanyak $62.82 \%$, sisanya berada pada kategori sedang sebanyak $37.18 \%$.

\section{DAFTAR PUSTAKA}

Anonim. (2012, 13 Maret). Indonesia Warriors vs Air Asia Philippine Patriots 10 Maret 2012 ABL Season Tiga. Retrieved from Sportku.com: http://basket.sportku.com/berita/komun itas/abl/10723-indonesia-warriors-vsair-asia-philippine-patriots-10-maret2012-abl-season-tiga diakses pada 7 Januari 2015.

Anonim. (2014, Mei). Individual Statistic Regular Season 2013-2014. Retrieved from Official Website Of National Basketball League Indonesia: http://www.nblindonesia.com/v1/index .php?page $=$ team_reg\&tahun $=2013$ diakses pada 5 Juli 2015.

Anonim. (2015, April). Individual Statistic Regular Season 2014-2015. Retrieved from Official Website Of National Basketball League Indonesia: http://www.nblindonesia.com/v1/index .php?page $=$ ind reg scoring $\mathrm{f} \&$ tahun $=$ $\underline{2014}$ diakses pada 4 Juli 2015.

Azwar, S. (2012). Penyusunan Skala Psikologi Edisi 2. Yogyakarta: Pustaka Pelajar.Bandura 96.

Bandura, A. (1997). Self Efficacy: The Exercise of Control. New York: Freeman and Company.

Budiwati, Etik. (2012). Hubungan Antara Locus of Control Internal dengan Kematangan Karir Pada Mahasiswa Psikologi Universitas Islam Negeri (UIN) Sunan Kali Jaga. skripsi, Tidak diterbitkan. Yogyakarta: Universitas Islam Negeri Sunan Kali Jaga.
Candi, Wawan. (2013). Pengaruh Bentuk Latihan Untuk Mengurangi Kecemasan Terhadap Hasil Free Throw (Tembakan Bebas) Cabang Olahraga Bola Basket Pada Atlet SMA Negeri 9 Bandung. skripsi, Tidak diterbitkan. Bandung: Universitas Pendidikan Indonesia.

Ghufron, M. \& Risnawita S, R. (2012). Teori-Teori Psikologi. Jogjakarta: ARRUZZ MEDIA.

Gunarsa, Singgih D. (1996). Psikologi Olah Raga:Teori dan Praktek. Jakarta: PT. BPK Gunung Mulia.

Harsono. (1988). Panduan Pengajar Buku Coaching dan Aspek-Aspek Psikologis Dalam Olahraga. Jakarta: Proyek Pengembangan Lembaga Pendidikan Tenaga Kependidikan.

Hurlock, E. B. (2002). Psikologi Perkembangan: Suatu Pendekatan Sepanjang Rentang Kehidupan. Surabaya: Erlangga.

Pesurnay, P. (2000). Reposisi dan Reaktualisasi Sistem Keolahragaan Menuju Indonesia Baru. Jawa Timur: Panitia Seminar Ilmiah PON XV.

Schultz, D. \& Schultz, S. E. (2002). Psychology dan Work Today. Eight Edition. New Jersey: Prentice Hall.

Taryono. (2010). Perbandingan Antara Latihan Kekuatan Otot Lengan Dengan Gerakan Bench Press Dan Push up Terhadap Hasil Tembakan Free Throw Dalam Permainan Bola Basket. Jurnal Motion Volume I. No. 1.

Wardhana, Seto. (2015, 11 Mei). Tekuk Pelita Jaya, Satria Muda Juara NBL 
2015. Retrieved from Tempo Sport: http://sport.tempo.co/read/news/2015/0 5/11/101665239/tekuk-pelita-jayasatria-muda-juara-nbl-2015 diakses pada 29 Juli 2015.

Wicaksono, J. A., \& Laksmiwati, H. (2013). Hubungan Self-efficacy Dengan Ketepatan Free Throw Pada Pemain National Basketball league Klub CLS Knight. Character, Vol. 01 No 02.

Wirtama, Ida B. S. (2014). Peran Hardiness dan Internal Locus Of Control Terhadap Self-Efficacy Pemain Sepak Bola dalam Melakukan Tendangan Pinalti. Skripsi, Tidak diterbitkan. Malang: Universitas Brawijaya.

Zulkaida, A., Kurniati, N.M., Muluk, H., \& Rifameutia, T. (2007). Pengaruh Locus of Conrol dan Efikasi Diri Terhadap Kematangan Karir Siswa Sekolah Menengah Atas (SMA). Jurnal Proceeding PESAT Vol 2. 